\title{
Comparison between different optimal strategies in Dual-channel supply chain inventory model
}

\author{
Emad Jacob Ibrahim and Sarah Ahmed Magdy* \\ Department of Mathematics, Faculty of Science, Ain Shams University, Abbassia, Cairo, Egypt
}

ARTICLE INFO

Article history:

Received 04 June 2016

Accepted 29 June 2016

Keywords:

Supply chain;

Inventory model;

Demand;

Uniform distribution;

e-tail channel.

\begin{abstract}
A B S T R A C T
This article considers a two-echelon dual channel supply chain where customers can purchase either from the retailer or order online from e-tail channel. It is assumed that the demand is lost if the customer didn't find the product in his preferable channel (i.e. customers have channel loyalty and not brand loyalty). The manufacturer is managing the inventory levels for retail and e-tail channels. Two different inventory strategies are discussed and for each strategy the optimal inventory levels in retail and e-tail stores and the respective expected profits are derived. Moreover, comparison between the performances of the two strategies is performed.
\end{abstract}

\section{List of Notations:}

\begin{tabular}{ll}
\hline$c_{i}$ & unit cost for channel $\mathrm{i}, \mathrm{i}=1,2$. \\
$\mathrm{d}$ & total demand on both channels \\
$\mathrm{d}_{\mathrm{i}}$ & demand for channel $\mathrm{i}, \mathrm{i}=1,2$. \\
$\mathrm{f}(\mathrm{d})$ & p.d.f. of the total demand $\mathrm{d}$ \\
$\mathrm{f}_{\mathrm{i}}\left(\mathrm{d}_{\mathrm{i}}\right)$ & p.d.f. of channel $\mathrm{i}, \mathrm{i}=1,2$. \\
$\mathrm{g}_{\mathrm{i}}$ & unit shortage cost for channel $\mathrm{i}, \mathrm{i}=1,2$. \\
$\mathrm{p}_{\mathrm{i}}$ & unit price for channel $\mathrm{i}, \mathrm{i}=1,2$. \\
$\mathrm{Q}_{\mathrm{i}}$ & inventory quantity for channel $\mathrm{i}, \mathrm{i}=1,2$. \\
$\mathrm{s}_{\mathrm{i}}$ & salvage value per unit of the product \\
& for channel $\mathrm{i}, \mathrm{i}=1,2$. \\
$\pi$ & total profit. \\
$\omega$ & wholesale price offered. \\
$\theta$ & demand splitting factor, $0<\theta<0.5$ \\
\hline
\end{tabular}

where, $i=1$ refers to e-tail channel and $i=2$ refers to retail channel
Firms following this dual-channel strategy are referred to as click-and-mortar companies, which is distinct from their traditional brick-and-mortar counterparts. Most of e-business failures are operations related. For example: one of the major reasons of lack of success for early e-business attempted was the failure of order fulfillment due to late delivery or stock out, especially during peak seasons like Christmas, Eid period, New Year.

Managing inventory effectively in both channels is a critical success factor for the survival of click-andmortar companies. Hill et al. ${ }^{[3]}$ stated that, currently, click-and-mortar firms are applying different inventory strategies for retail and e-tail channels. For example, some firms use a strategy to segregate retail and e-tail channels, each channel having its own warehouse, and keep the e-tail in-house. The advantage of this strategy is 
that inventory levels of both channels are not intermingled, and, therefore, fulfillment quantity in each channel is assured. The disadvantage is that some of the firms find that it's hard to manage inventory for the same product in two different channels and, therefore, outsource thee-tail channel to third party firms having expertise in the order fulfillment process of this kind. Another strategy commonly used called professional shopper strategy, where customers first surf online for product information on an e-tail store, and then make the purchase in a retail store. Alternatively, they order online, and then pick up the product in a retail store, i.e., e-tailers partner with the retailer for the order fulfillment process. Lee and Whang ${ }^{[4]}$ list this as one of the five strategies to win the last mile of e-commerce.

The business practices detailed above raise the following interesting research question for supply chain management: what are the optimal inventory decisions for the retail and e-tail stores for different e-business strategies? An additional motivation is to determine not only the inventory level in retail channel but also in the e-tail channel. We consider the situation where demands in the two channels are related, and customers are split between the two channels. In this paper we are concerned about the optimal inventory levels in each channel where the two-stage supply chain is facing random demand.

We consider two different channel strategies found in practice. All of them are for a two-stage supply chain with one manufacturer and a retailer. There is also a different channel from the manufacturer to customer the e-tail channel. These strategies are:

(1) Centralized Inventory Strategy.

The manufacturer owns both retail and e-tail channels and has full control of the inventory decisions. Therefore, there is only one centralized decision maker.

\section{(2) Stackelberg (Leader-follower) inventory strategy.}

In this case, the manufacturer owns the e-tail store whereas the retailer controls the retail store. The manufacturer has full control of the inventory level in etail store and the wholesale price to the retailer. In response to the wholesale price, the retailer, acting as the follower in the game, makes inventory decisions for the retailer channel. In order to integrate internet fulfillment operations into their distribution networks, a number of manufacturers use this option to add an e-tail channel and has full control of it.

This article presents and compares the optimal inventory levels for retail and e-tail channels for both Centralized Inventory and Stackelberg inventory strategies. Section 2 presents survey of recent literature. We present our model and analyze the centralized strategy in Section 3. Optimal inventory levels for retail and e-tail stores for the Stackelberg strategy are presented in Section 4.The closed form of the optimal manufacturer's expected profits for the different strategies are derived in Section 5.The performance analysis of the two strategies is presented by numerical example in Section 6 .

\section{Literature Review}

The optimal inventory decisions in a multi-channel setting and its impact on a firm's performance affects related fields like marketing, economics and management science. From the marketing point of view, a buyer's evaluation of an e-tailer's delivery performance can be positively impacted by the firm's inventory policy. This has been empirically shown by Cao and Zhao ${ }^{[5]}$. Hua and $\mathrm{Li}^{[6]}$ studied the effect of retail market demand uncertainty on the retailer's dominance over the manufacturer using a co-operative game scenario. An extensive study from operations point of view is reported by Khouja ${ }^{[7]}$. He studied three different demand distributions, namely, exponential, normal, and uniform, and evaluated optimal ordering levels for both in-house and drop-shipping inventory.

We can categorize the multi-channel inventory research into two streams:

Stream (1): the demand in each channel is independent, random from a given distribution, or with correlation between individual demands. The total channel demand, characterizing the industry demand, is the aggregation of the individual channel demands. The effect of information sharing for resolving shipment quantity uncertainty was studied by Zhang et al. ${ }^{[8]}$. They found that when advance shipping notice is used to share information, it would resolve the uncertainty well. Lee ${ }^{[9]}$ considers a single manufacturer-single buyer supply chain where the manufacturer satisfies a constant demand rate by fixed lot size delivery. An integrated inventory control model to minimize mean total cost per unit is presented.

Abdul-Jalbar et al. ${ }^{[10]}$ studied a multi-echelon inventory supply chain with one warehouse and multiple retailers. The demand of each retailer is known and constant. Seifert et al. ${ }^{[11]}$ analyzed how to integrate an online store into an established supply chain by allowing for transshipment from retail stores to online store. They assumed the demands of retail stores and online store are independent, which make their analysis somewhat tractable. They quantify the expected cost savings of an integrated supply chain over a dedicated one, which also results in a higher consumer service level.

Stream (2): the total demand comes from a certain distribution. This total demand is split among the channels. This is in contrast to the first stream where the individual channel demands are aggregated into industry demand. To allocate the industry demand among the firms, they use one of four splitting rules, namely: deterministic splitting, simple random splitting, Incremental random splitting and independent random demand. Of these four rules, we feel that the deterministic demand splitting rule is appropriate for the scenario of e-tail and retail channels in our paper. Tsay and Agrawal ${ }^{[12]}$ studied how a direct channel and a reseller channel are interested to know the allocation of demand between the two channels. The authors modeled the demand allocation with a fraction of the effort-driven 
component of the total demand captured by direct channel.

\section{The Model}

A supply chain with retail and e-tail channel selling short life cycle goods (like: fashion wear, hi-tech products) is considered. Customers have the choice of purchasing either from normal retail store or order online directly from the manufacturer. We assume that the demand is random variable and that a certain fraction of customers prefer retail stores, whereas the remainder prefers making online purchases $\left[d=d_{2}+d_{1}\right]$. The model decides about the inventory level that maximizes profit for single period under probabilistic demand. It is assumed that, if a customer's demand couldn't be met through his selected channel, the demand is lost, which is reasonable for customers with channel loyalty but no brand loyalty. In addition, if a product is out of stock in a channel, there is no transshipment from the other channel. This is most likely to happen in short selling seasons like holidays (Christmas, Easter, etc) so that there is no enough time for transshipment between different stores. Figure (1), illustrates the problem. This article is interesting in analyzing the optimal inventory levels of retail and e-tail stores, for different strategies, and their effects on the manufacturer's profits.

For simplicity we will not consider the holding cost, which could be adjusted by subtracting the holding cost from the salvage value as suggested by Parlar ${ }^{[13]}$.

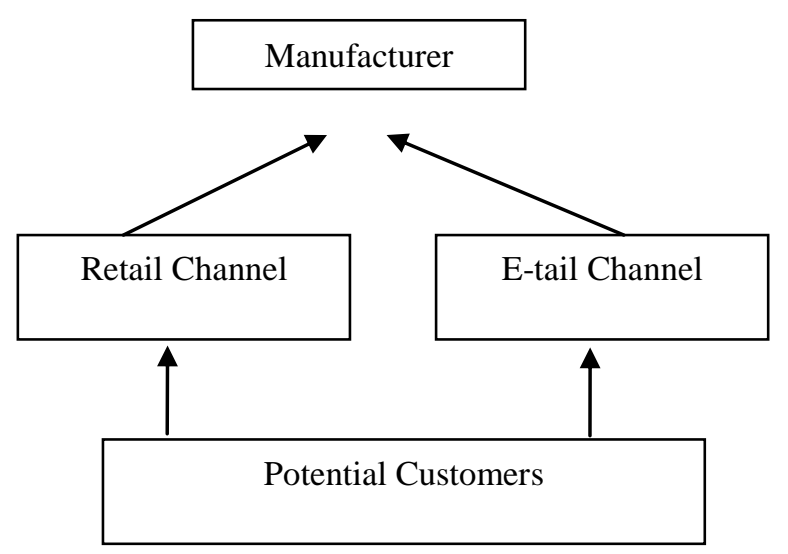

Fig. (1): Retail and e-tail demand distribution

\section{Demand Split}

We assume that the total demand (d) via both channels is a random variable, and customers are split between the two channels (online and retail). Demand function for online channel is $d_{1}=s(d)$ say, and the demand for retail channel is $d_{2}=d-s(d)$.

We assume that the e-tail customers have the following two properties:

1- A new customer is more likely to use e-tail channel than retail channel. i.e. $s^{\prime}(d)>0$ and $s^{\prime \prime}(d)>0$ [14]. This assumption is due to the following facts: customers are more comfortable with the e-tail channel and increasing due to internet security and online shopping has become more convenient as a shopping option. In addition to, it can penetrate into potential markets that are generally not accessible by retail stores. Finally, customers are not stick to store opening hours and orders can be easily personalized by web technologies.

2- The size of online customers is still relatively small compared with retail store customers.

We assume that the total demand is uniformly distributed because uniform distribution is bounded and tractable, i.e. $d \sim U[a, b]$. The assumption of uniform distribution is general enough to capture the essential dynamics of demand split between e-tail and retail stores. For this reason, it's commonly used in supply chain literature. Based on the above properties for e-tail customers, we assume the demand via e-tail channel $s(d)=\theta\left(\frac{d}{b-a}\right)^{2}$ according to property 1 above where, $0<\theta<0.5$ according to property 2 . We have the following lemma regarding the probability density functions for customers in retail and e-tail stores.

\section{Lemma 1}

$$
\begin{aligned}
& \text { If } \quad \mathrm{f}(\mathrm{d})=\frac{1}{\mathrm{~b}-\mathrm{a}} \quad \mathrm{f}_{1}\left(\mathrm{~d}_{1}\right)=\frac{1}{2 \sqrt{\theta \mathrm{d}_{1}}}, 0 \leq \mathrm{d}_{1} \leq \theta \\
& \mathrm{f}_{2}\left(\mathrm{~d}_{2}\right)=\frac{1}{\sqrt{(\mathrm{b}-\mathrm{a})^{2}-4 \theta \mathrm{d}_{2}}}, \quad 0 \leq \mathrm{d}_{2} \leq 1-\theta
\end{aligned}
$$

Proof: It is known that if $\mathrm{Y}=\mathrm{g}(\mathrm{X})$ has a one - to - one mapping, then the p.d.f of $\mathrm{Y}$ can be obtained from the p.d.f of $\mathrm{X}$ using

$$
f_{Y}(y)=f_{X}\left|g^{-1}(y)\right| \frac{d g^{-1}(y)}{d y} \mid \text {. }
$$

$$
\text { In our case, } \quad d_{1}=\theta\left(\frac{d}{b-a}\right)^{2}, \quad d=(b-a) \sqrt{\frac{d_{1}}{\theta}}, \quad \text { then }
$$$$
\mathrm{f}_{1}\left(\mathrm{~d}_{1}\right)=\frac{1}{2 \sqrt{\theta \mathrm{d}_{1}}}
$$

Similarly, $\mathrm{d}_{2}=\mathrm{d}-\theta\left(\frac{\mathrm{d}}{\mathrm{b}-\mathrm{a}}\right)^{2}$, so

$d=\frac{(b-a)^{2} \pm \sqrt{(b-a)^{4}-4 \theta(b-a)^{2} d_{2}}}{2 \theta}=(b-a)\left[\frac{(b-a) \pm \sqrt{(b-a)^{2}-4 \theta d_{2}}}{2 \theta}\right]$, Because $\theta<0.5, \quad d=(b-a)\left[\frac{(b-a)+\sqrt{(b-a)^{2}-4 \theta d_{2}}}{2 \theta}\right]>(b-a)$ which is infeasible and is therefore rejected. So, we have

$$
d=(b-a)\left[\frac{(b-a)-\sqrt{(b-a)^{2}-4 \theta d_{2}}}{2 \theta}\right]
$$

$$
\text { Therefore, } \mathrm{f}_{2}\left(\mathrm{~d}_{2}\right)=\frac{1}{\sqrt{(\mathrm{b}-\mathrm{a})^{2}-4 \theta \mathrm{d}_{2}}}
$$

Based on Lemma 1, the demands on dual channels are decomposed into two separate variables with different probability distributions. In our analysis, we will use these demand distributions for the retail and e-tail channels to obtain each player's expected profit. In the next section, we will study the first of our strategies, namely the centralized inventory strategy.

\section{Centralized inventory strategy}

This is a strategy where a centralized decision to handle shipments to retail stores as well as to online orders is made. The manufacturer has full control of both retail and e-tail channels. 
The decision variables here are $\mathrm{Q}_{1}$ and $\mathrm{Q}_{2}$. Eq. (3.2) is the total expected profit for two channels:

$$
\begin{aligned}
E[\pi]=-c_{1} Q_{1}-c_{2} Q_{2} & +\int_{0}^{Q_{1}}\left[p_{1} d_{1}+s_{1}\left(Q_{1}-d_{1}\right)\right] f\left(d_{1}\right) d\left(d_{1}\right)+\int_{Q_{1}}^{\theta}\left[p_{1} Q_{1}-g_{1}\left(d_{1}-Q_{1}\right)\right] f\left(d_{1}\right) d\left(d_{1}\right) \\
& +\int_{0}^{Q_{2}}\left[p_{2} d_{2}+s_{2}\left(Q_{2}-d_{2}\right)\right] f\left(d_{2}\right) d\left(d_{2}\right)+\int_{Q_{2}}^{1-\theta}\left[p_{2} Q_{2}-g_{2}\left(d_{2}-Q_{2}\right)\right] f\left(d_{2}\right) d\left(d_{2}\right)
\end{aligned}
$$

Where,

$\mathrm{c}_{1} \mathrm{Q}_{1}$ and $\mathrm{c}_{2} \mathrm{Q}_{2}$ are the costs associated with inventories $\mathrm{Q}_{1}$ and $\mathrm{Q}_{2}$.

$$
\int_{0}^{\mathrm{Q}_{1}}\left[\mathrm{p}_{1} \mathrm{~d}_{1}+\mathrm{s}_{1}\left(\mathrm{Q}_{1}-\mathrm{d}_{1}\right)\right] \mathrm{f}\left(\mathrm{d}_{1}\right) \mathrm{d}\left(\mathrm{d}_{1}\right)
$$

is the expected profit when the demand $d_{1}$ is less than or equal to the inventory level $Q_{1}$ (consisting of the revenue for $d_{1}$ and the salvage value for the unsold items).

$$
\int_{\mathrm{Q}_{1}}^{\theta}\left[\mathrm{p}_{1} \mathrm{Q}_{1}-\mathrm{g}_{1}\left(\mathrm{~d}_{1}-\mathrm{Q}_{1}\right)\right] \mathrm{f}\left(\mathrm{d}_{1}\right) \mathrm{d}\left(\mathrm{d}_{1}\right)
$$

is the expected profit

when the demand is greater than the inventory level up to the maximum possible value of $\theta$. This is the revenue value generated by selling $Q_{1}$ units less than the shortage cost for the unsatisfied demand.

$$
\int_{0}^{Q_{2}}\left[p_{2} d_{2}+s_{2}\left(Q_{2}-d_{2}\right)\right] f\left(d_{2}\right) d\left(d_{2}\right)
$$$$
\int_{\mathrm{Q}_{2}}^{1-\theta}\left[\mathrm{p}_{2} \mathrm{Q}_{2}-\mathrm{g}_{2}\left(\mathrm{~d}_{2}-\mathrm{Q}_{2}\right)\right] \mathrm{f}\left(\mathrm{d}_{2}\right) \mathrm{d}\left(\mathrm{d}_{2}\right)
$$

retail channel.

In the following theorem we will get the optimal inventory decisions for both retail and e-tail stores.

Theorem 1: The optimal stocking size for online and retail stores are as follows:

$$
\begin{aligned}
& Q_{1}^{*}=\theta\left[\frac{p_{1}+g_{1}-c_{1}}{p_{1}+g_{1}-s_{1}}\right]^{2} \\
& Q_{2}^{*}=\frac{1}{4 \theta}\left[(b-a)^{2}-\left(\frac{2 \theta c_{2}-(b-a) s_{2}}{p_{2}+g_{2}-s_{2}}+\frac{p_{2}+g_{2}}{p_{2}+g_{2}-s_{2}} \sqrt{(b-a)^{2}-4 \theta(1-\theta)}\right)^{2}\right]
\end{aligned}
$$

\section{Proof:}

In model (3.2) the optimum values $\left(\mathrm{Q}_{1}^{*}, \mathrm{Q}_{2}^{*}\right)$ are found by setting the partial derivatives $\frac{\partial \mathrm{E}[\pi]}{\partial \mathbf{Q}_{1}}$ and $\frac{\partial \mathrm{E}[\pi]}{\partial \mathbf{Q}_{2}}$ equal to zero, and solving for $\mathrm{Q}_{1}$ and $\mathrm{Q}_{2}$ substituting for $\mathrm{f}_{1}\left(\mathrm{~d}_{1}\right)$ and $\mathrm{f}_{2}\left(\mathrm{~d}_{2}\right)$ from Lemma 1 .

$$
\begin{aligned}
& \frac{\partial \mathrm{E}[\pi]}{\partial \mathrm{Q}_{1}}=-\mathrm{c}_{1}+\mathrm{s}_{1} \int_{0}^{\mathrm{Q}_{1}} \mathrm{f}\left(\mathrm{d}_{1}\right) \mathrm{d}\left(\mathrm{d}_{1}\right)+\left(\mathrm{p}_{1}+\mathrm{g}_{1}\right) \int_{\mathrm{Q}_{1}}^{\theta} \mathrm{f}\left(\mathrm{d}_{1}\right) \mathrm{d}\left(\mathrm{d}_{1}\right)=0 \\
& -\mathrm{c}_{1}+\mathrm{s}_{1} \int_{0}^{\mathrm{Q}_{1}} \frac{1}{2 \sqrt{\theta \mathrm{d}_{1}}} \mathrm{~d}\left(\mathrm{~d}_{1}\right)+\left(\mathrm{p}_{1}+\mathrm{g}_{1}\right) \int_{\mathrm{Q}_{1}}^{\theta} \frac{1}{2 \sqrt{\theta \mathrm{d}_{1}}} \mathrm{~d}\left(\mathrm{~d}_{1}\right)=0 \\
& -\mathrm{c}_{1}+\mathrm{s}_{1} \sqrt{\frac{\mathrm{Q}_{1}^{*}}{\theta}}+\left(\mathrm{p}_{1}+\mathrm{g}_{1}\right)\left(1-\sqrt{\frac{\mathrm{Q}_{1}^{*}}{\theta}}\right)=0 \\
& \frac{\mathrm{p}_{1}+\mathrm{g}_{1}-\mathrm{c}_{1}}{\mathrm{p}_{1}+\mathrm{g}_{1}-\mathrm{s}_{1}}=\sqrt{\frac{\mathrm{Q}_{1}^{*}}{\theta}} \\
& \mathrm{Q}_{1}^{*}=\theta\left(\frac{\mathrm{p}_{1}+\mathrm{g}_{1}-\mathrm{c}_{1}}{\mathrm{p}_{1}+\mathrm{g}_{1}-\mathrm{s}_{1}}\right)^{2}
\end{aligned}
$$

And by the same way we get

$$
\begin{aligned}
& \frac{\partial \mathrm{E}[\pi]}{\partial \mathrm{Q}_{2}}=-\mathrm{c}_{2}+\mathrm{s}_{2} \int_{0}^{\mathrm{Q}_{2}} \mathrm{f}\left(\mathrm{d}_{2}\right) \mathrm{d}\left(\mathrm{d}_{2}\right)+\left(\mathrm{p}_{2}+\mathrm{g}_{2}\right) \int_{\mathrm{Q}_{2}}^{1-\theta} \mathrm{f}\left(\mathrm{d}_{2}\right) \mathrm{d}\left(\mathrm{d}_{2}\right)=0 \\
& -\mathrm{c}_{2}+\mathrm{s}_{2} \int_{0}^{\mathrm{Q}_{2}} \frac{1}{\sqrt{(\mathrm{b}-\mathrm{a})^{2}-4 \theta \mathrm{d}_{2}}} \mathrm{~d}\left(\mathrm{~d}_{2}\right)+\left(\mathrm{p}_{2}+\mathrm{g}_{2}\right) \int_{\mathrm{Q}_{2}}^{1-\theta} \frac{1}{\sqrt{(b-a)^{2}-4 \theta \mathrm{d}_{2}}} \mathrm{~d}\left(\mathrm{~d}_{2}\right)=0 \\
& \frac{2 \theta \mathrm{c}_{2}-(\mathrm{b}-\mathrm{a}) \mathrm{s}_{2}}{\mathrm{p}_{2}+\mathrm{g}_{2}-\mathrm{s}_{2}}+\frac{\mathrm{p}_{2}+\mathrm{g}_{2}}{\mathrm{p}_{2}+\mathrm{g}_{2}-\mathrm{s}_{2}} \sqrt{(\mathrm{b}-\mathrm{a})^{2}-4 \theta(1-\theta)}=\sqrt{(\mathrm{b}-\mathrm{a})^{2}-4 \theta \mathrm{Q}_{2}^{*}}
\end{aligned}
$$

Then

$\mathrm{Q}_{2}^{*}=\frac{1}{4 \theta}\left[(\mathrm{b}-\mathrm{a})^{2}-\left(\frac{2 \theta \mathrm{c}_{2}-(\mathrm{b}-\mathrm{a}) \mathrm{s}_{2}}{\mathrm{p}_{2}+\mathrm{g}_{2}-\mathrm{s}_{2}}+\frac{\mathrm{p}_{2}+\mathrm{g}_{2}}{\mathrm{p}_{2}+\mathrm{g}_{2}-\mathrm{s}_{2}} \sqrt{(\mathrm{b}-\mathrm{a})^{2}-4 \theta(1-\theta)}\right)^{2}\right]$

It is clear that

$$
\begin{aligned}
& \frac{\partial^{2} E[\pi]}{\partial Q_{1}^{2}}=s_{1} f\left(Q_{1}\right)-\left(p_{1}+g_{1}\right) f\left(Q_{1}\right)=\left(s_{1}-p_{1}-g_{1}\right) f\left(Q_{1}\right)=-\left(p_{1}+g_{1}-s_{1}\right) f\left(Q_{1}\right)<0 \\
& \frac{\partial^{2} E[\pi]}{\partial Q_{2}^{2}}=s_{2} f\left(Q_{2}\right)-\left(p_{2}+g_{2}\right) f\left(Q_{2}\right)=-\left(p_{2}+g_{2}-s_{2}\right) f\left(Q_{2}\right)<0
\end{aligned}
$$

Then $E[\pi]$ has maximum value at $\left(Q_{1}^{*}, Q_{2}^{*}\right)$.

We will use the centralized strategy as a benchmark for the next strategy studied in Section 4. We study a competitive game between the two channels where one firm, namely the manufacturer, acts as the leader.

\section{Stackelberg (Leader-follower) inventory strategy}

This strategy is more realistic because the two channels "e-tail and retail" are de facto competitors and accordingly would make decisions separately keeping their own interests in mind. The manufacturer will have full control of the online channel and is assumed to be the Stackelberg inventory leader while the retailer is the follower. Here how it goes:

(i) The manufacture makes decisions for the e-tail inventory level $\mathrm{Q}_{1}$ and wholesale price $\omega$ offered to the retailer in order to maximize its expected profit, given the expected response function of the retailer.

(ii) In response to the manufacturer's wholesale price $\omega$, the retailer places an order to the manufacturer to stock an inventory level $\mathrm{Q}_{2}$ in order to maximize retailer own expected profit.

To solve a two-stage Stackelberg game like this we need to solve the retailer's objective function first to obtain the follower's response function as a function of the leader's decision variables.

\section{The retailer's problem}

The retailer's expected profit given $\omega$ is $E\left[\pi_{2} \mid \omega\right]=-\omega Q_{2}+\int_{0}^{Q_{2}}\left[p_{2} d_{2}+s_{2}\left(Q_{2}-d_{2}\right)\right] f\left(d_{2}\right) d\left(d_{2}\right)+\int_{Q_{2}}^{1-\theta}\left[p_{2} Q_{2}-g_{2}\left(d_{2}-Q_{2}\right)\right] f\left(d_{2}\right) d\left(d_{2}\right)$

where $1-\theta$ is the retailer's maximum demand. The next theorem gives the best response function of the follower given $\omega$. 
Theorem 2: The retailer's best inventory response function is

$$
\mathrm{Q}_{2}^{\mathrm{s}^{*}}=\frac{1}{4 \theta}\left[(\mathrm{b}-\mathrm{a})^{2}-\left(\frac{2 \theta \omega-(\mathrm{b}-\mathrm{a}) \mathrm{s}_{2}}{\mathrm{p}_{2}+\mathrm{g}_{2}-\mathrm{s}_{2}}+\frac{\mathrm{p}_{2}+\mathrm{g}_{2}}{\mathrm{p}_{2}+\mathrm{g}_{2}-\mathrm{s}_{2}} \sqrt{(\mathrm{b}-\mathrm{a})^{2}-4 \theta(1-\theta)}\right)^{2}\right]
$$

Proof: Similar to Theorem 1.

A comparison with the benchmark case (Theorem1) shows that in case $\omega=c_{2}$, the inventory level of the retailer would be the same as in Theorem 1 .

\section{The manufacturer's problem}

The next step in solving Stackelberg game is to find the manufacturer's (the leader) optimum policy given the follower's best response function. The manufacturer's objective is as follows:

$\underset{Q_{1}, \omega}{\operatorname{Max}} E\left[\pi_{1}\right]=-c_{1} Q_{1}+\left(\omega-c_{2}\right) Q_{2}+\int_{0}^{Q_{1}}\left[p_{1} d_{1}+s_{1}\left(Q_{1}-d_{1}\right)\right] f\left(d_{1}\right) d\left(d_{1}\right)+\int_{Q_{1}}^{\theta}\left[p_{1} Q_{1}-g_{1}\left(d_{1}-Q_{1}\right)\right] f\left(d_{1}\right) d\left(d_{1}\right)$

Solve this problem to optimality and obtain the optimal policies for the manufacturer as given in the next theorem.

Theorem 3: The manufacturer's optimal decisions are:

$$
\omega^{*}=\frac{-\alpha+\sqrt{\alpha^{2}-12 \theta \beta}}{6 \theta} \quad \mathrm{Q}_{1}^{\mathrm{s}^{*}}=\theta\left[\frac{\mathrm{p}_{1}+\mathrm{g}_{1}-\mathrm{c}_{1}}{\mathrm{p}_{1}+\mathrm{g}_{1}-\mathrm{s}_{1}}\right]^{2}
$$

\section{where,}

$$
\begin{aligned}
\alpha= & 2\left(p_{2}+g_{2}\right) \sqrt{(b-a)^{2}-4 \theta(1-\theta)}-2(b-a) s_{2}-2 \theta c_{2} \\
\beta= & \frac{(b-a)\left(p_{2}+g_{2}\right) s_{2}}{2 \theta}\left[(b-a)-\sqrt{(b-a)^{2}-4 \theta(1-\theta)}\right]+ \\
& {\left[(b-a) s_{2} c_{2}-(1-\theta)\left(p_{2}+g_{2}\right)^{2}-c_{2}\left(p_{2}+g_{2}\right) \sqrt{(b-a)^{2}-4 \theta(1-\theta)}\right] }
\end{aligned}
$$

Theorem 3 gives the closed-form solutions of the manufacturer's optimal decisions for his e-tail stores.

\section{Proof:}

We have

$$
\frac{\partial \mathrm{Q}_{2}^{\mathrm{s}^{*}}}{\partial \omega}=\frac{(\mathrm{b}-\mathrm{a}) \mathrm{s}_{2}-2 \theta \omega}{\left(\mathrm{p}_{2}+\mathrm{g}_{2}-\mathrm{s}_{2}\right)^{2}}-\frac{\mathrm{p}_{2}+\mathrm{g}_{2}}{\left(\mathrm{p}_{2}+\mathrm{g}_{2}-\mathrm{s}_{2}\right)^{2}} \sqrt{(\mathrm{b}-\mathrm{a})^{2}-4 \theta(1-\theta)}
$$

which implies

$$
\begin{aligned}
& \frac{\partial^{2} \mathrm{Q}_{2}^{\mathrm{s}^{*}}}{\partial \omega^{2}}=\frac{-2 \theta}{\left(\mathrm{p}_{2}+\mathrm{g}_{2}-\mathrm{s}_{2}\right)^{2}}<0 \\
& \frac{\partial \mathrm{E}\left[\pi_{1}\right]}{\partial \omega}=\mathrm{Q}_{2}^{\mathrm{s}^{*}}+\left(\omega-\mathrm{c}_{2}\right) \frac{\partial \mathrm{Q}_{2}^{\mathrm{s}^{*}}}{\partial \omega} \\
& \frac{\partial^{2} \mathrm{E}\left[\pi_{1}\right]}{\partial \omega^{2}}=2 \frac{\partial \mathrm{Q}_{2}^{\mathrm{s}}}{\partial \omega}+\left(\omega-\mathrm{c}_{2}\right) \frac{\partial^{2} \mathrm{Q}_{2}^{\mathrm{s}^{*}}}{\partial \omega^{2}} \\
& \quad=2 \frac{\partial \mathrm{Q}_{2}^{\mathrm{s}^{*}}}{\partial \omega}-\left(\omega-\mathrm{c}_{2}\right) \frac{2 \theta}{\left(\mathrm{p}_{2}+\mathrm{g}_{2}-\mathrm{s}_{2}\right)^{2}}
\end{aligned}
$$

It is easy to show that $\frac{\partial \mathbf{Q}_{2}^{\mathrm{s}^{*}}}{\partial \omega}<0$ if $\omega \geq \mathrm{c}_{2}$, therefore, $\frac{\partial^{2} E\left[\pi_{1}\right]}{\partial \omega^{2}}<0$ and unique maximum of $\omega^{*} \geq c_{2}$ can be found.

Using (4.2) and (4.3) we get, $\frac{1}{4 \theta}\left[(b-a)^{2}-\left(\frac{2 \theta \omega-(b-a) s_{2}}{p_{2}+g_{2}-s_{2}}+\frac{p_{2}+g_{2}}{p_{2}+g_{2}-s_{2}} \sqrt{(b-a)^{2}-4 \theta(1-\theta)}\right)^{2}\right]+$

$\left(\omega-c_{2}\right)\left[\frac{(b-a) s_{2}-2 \theta \omega}{\left(p_{2}+g_{2}-s_{2}\right)^{2}}+\frac{p_{2}+g_{2}}{\left(p_{2}+g_{2}-s_{2}\right)^{2}} \sqrt{(b-a)^{2}-4 \theta(1-\theta)}\right]=0$

Making some simplifications we get

$3 \theta \omega^{2}+\left[2\left(p_{2}+g_{2}\right) \sqrt{(b-a)^{2}-4 \theta(1-\theta)}-2(b-a) s_{2}-2 \theta c_{2}\right] \omega+$

$\left[\begin{array}{l}\left(\frac{1}{2 \theta}(b-a)\left(p_{2}+g_{2}\right) s_{2}\left((b-a)-\sqrt{(b-a)^{2}-4 \theta(1-\theta)}\right)\right)+ \\ \left((b-a) s_{2} c_{2}-(1-\theta)\left(p_{2}+g_{2}\right)^{2}-c_{2}\left(p_{2}+g_{2}\right) \sqrt{(b-a)^{2}-4 \theta(1-\theta)}\right)\end{array}\right]=0$

Which can be written as: $3 \theta \omega^{2}+\omega \alpha+\beta=0$

where,

$$
\begin{aligned}
\alpha= & 2\left(p_{2}+g_{2}\right) \sqrt{(b-a)^{2}-4 \theta(1-\theta)}-2(b-a) s_{2}-2 \theta c_{2} \\
\beta= & \frac{(b-a)\left(p_{2}+g_{2}\right) s_{2}}{2 \theta}\left[(b-a)-\sqrt{(b-a)^{2}-4 \theta(1-\theta)}\right]+ \\
& {\left[(b-a) s_{2} c_{2}-(1-\theta)\left(p_{2}+g_{2}\right)^{2}-c_{2}\left(p_{2}+g_{2}\right) \sqrt{(b-a)^{2}-4 \theta(1-\theta)}\right] }
\end{aligned}
$$

So the optimal wholesale price is $\omega^{*}=\frac{-\alpha+\sqrt{\alpha^{2}-12 \theta \beta}}{6 \theta}$

The proof of $Q_{1}^{s^{*}}$ is similar to that for $Q_{1}^{*}$ in Theorem1.

The computational form for the optimal expected profit functions

(i) The closed form of the manufacturer's expected profit for centralized inventory strategy

$\int_{0}^{\mathrm{Q}_{1}}\left[\mathrm{p}_{1} \mathrm{~d}_{1}+\mathrm{s}_{1}\left(\mathrm{Q}_{1}-\mathrm{d}_{1}\right)\right] \mathrm{f}\left(\mathrm{d}_{1}\right) \mathrm{d}\left(\mathrm{d}_{1}\right)=\int_{0}^{\mathrm{Q}_{1}}\left[\mathrm{p}_{1} \mathrm{~d}_{1}+\mathrm{s}_{1}\left(\mathrm{Q}_{1}-\mathrm{d}_{1}\right)\right] \frac{1}{2 \sqrt{\theta \mathrm{d}_{1}}} \mathrm{~d}\left(\mathrm{~d}_{1}\right)=\frac{\mathrm{Q}_{1}}{3} \sqrt{\frac{\mathrm{Q}_{1}}{\theta}}\left[\mathrm{p}_{1}+2 \mathrm{~s}\right.$

$$
\begin{aligned}
\int_{Q_{1}}^{\theta}\left[p_{1} Q_{1}-g_{1}\left(d_{1}-Q_{1}\right)\right] f\left(d_{1}\right) d\left(d_{1}\right) & =\int_{Q_{1}}^{\theta}\left[p_{1} Q_{1}-g_{1}\left(d_{1}-Q_{1}\right)\right] \frac{1}{2 \sqrt{\theta d_{1}}} d\left(d_{1}\right) \\
& =\left(p_{1}+g_{1}\right) Q_{1}-p_{1} Q_{1} \sqrt{\frac{Q_{1}}{\theta}}-\frac{2 \mathrm{~g}_{1} Q_{1}}{3} \sqrt{\frac{Q_{1}}{\theta}}-\frac{g_{1}}{3} \theta
\end{aligned}
$$

$$
\begin{aligned}
& \int_{0}^{\mathrm{Q}_{2}}\left[\mathrm{p}_{2} \mathrm{~d}_{2}+\mathrm{s}_{2}\left(\mathrm{Q}_{2}-\mathrm{d}_{2}\right)\right] \mathrm{f}\left(\mathrm{d}_{2}\right) \mathrm{d}\left(\mathrm{d}_{2}\right)=\int_{0}^{\mathrm{Q}_{2}}\left[\mathrm{p}_{2} \mathrm{~d}_{2}+\mathrm{s}_{2}\left(\mathrm{Q}_{2}-\mathrm{d}_{2}\right)\right] \frac{1}{\sqrt{(\mathrm{b}-\mathrm{a})^{2}-4 \theta \mathrm{d}_{2}}} \mathrm{~d}\left(\mathrm{~d}_{2}\right) \\
& =\frac{\left(\mathrm{p}_{2}-\mathrm{s}_{2}\right)}{(4 \theta)^{2}}\left[\frac{4}{3}(\mathrm{~b}-\mathrm{a})^{2}-2(\mathrm{~b}-\mathrm{a})^{2} \sqrt{(\mathrm{b}-\mathrm{a})^{2}-4 \theta \mathrm{Q}_{2}}+\frac{2}{3} \sqrt{\left((\mathrm{b}-\mathrm{a})^{2}-4 \theta \mathrm{Q}_{2}\right)^{3}}\right]+ \\
& \frac{\mathrm{s}_{2} \mathrm{Q}_{2}}{2 \theta}\left[(\mathrm{b}-\mathrm{a})-\sqrt{(\mathrm{b}-\mathrm{a})^{2}-4 \theta \mathrm{Q}_{2}}\right]
\end{aligned}
$$

$$
\begin{aligned}
& \int_{Q_{2}}^{1-\theta}\left[p_{2} Q_{2}-g_{2}\left(d_{2}-Q_{2}\right)\right] f\left(d_{2}\right) d\left(d_{2}\right) \\
& =\int_{Q_{2}}^{1-\theta}\left[p_{2} Q_{2}-g_{2}\left(d_{2}-Q_{2}\right)\right] \frac{1}{\sqrt{(b-a)^{2}-4 \theta d_{2}}} d\left(d_{2}\right) \\
& =\frac{\left(p_{2}+g_{2}\right) Q_{2}}{2 \theta}\left[\sqrt{(b-a)^{2}-4 \theta Q_{2}}-\sqrt{(b-a)^{2}-4 \theta(1-\theta)}\right]+ \\
& \frac{g_{2}}{(4 \theta)^{2}}\left[\begin{array}{l}
2(b-a)^{2} \sqrt{(b-a)^{2}-4 \theta(1-\theta)}-2(b-a)^{2} \sqrt{(b-a)^{2}-4 \theta Q_{2}}- \\
\frac{2}{3} \sqrt{\left((b-a)^{2}-4 \theta(1-\theta)\right)^{3}}+\frac{2}{3} \sqrt{\left.(b-a)^{2}-4 \theta Q_{2}\right)^{3}}
\end{array}\right]
\end{aligned}
$$


Now replacing $\left(Q_{1}, Q_{2}\right)$ by their optimal values $\left(Q_{1}^{*}, Q_{2}^{*}\right)$ and substituting by (5.1) to (5.4) in the main equation (3.2) we obtain the optimum value of the manufacturer's expected profit for Centralized inventory strategy $\mathrm{E}\left[\pi_{1}^{*}\right]$ (ii) The closed form of the manufacturer's expected profit for Stackelberg strategy

By the same way as previous we get $\mathrm{E}\left[\pi_{1}^{\mathrm{s}^{*}}\right]=\left(\omega^{*}-\mathrm{c}_{2}\right) \mathrm{Q}_{2}^{\mathrm{s}^{*}}+\frac{1}{3}\left(\mathrm{p}_{1}+\mathrm{g} 1-\mathrm{c}_{1}\right) \mathrm{Q}_{1}^{\mathrm{S}^{*}}-\frac{1}{3} \mathrm{~g}_{1} \theta$

\section{Numerical Example}

In order to examine the model behavior, we proceeded to optimize the system under 30 sets of parameter values. Table (1) contains the parameters of 30 examples. We compare the optimal profits for the Centralized strategy and Stackelberg strategy. For $\theta=0.1,0.2,0.3,0.4$ and 0.5 we see that, the profit increases with $\theta$.

In most cases the expected manufacture's profit for the Stackelberge case is greater than the expected manufacturer's profit for the Centralized case.

Table 1: Comparison between total inventory levels and expected manufacturer's profit for Centralized and Stackelberg strategies

\begin{tabular}{|c|c|c|c|c|c|c|c|}
\hline Example & $\begin{array}{c}\mathbf{Q}_{1}^{*}=\mathbf{Q}_{1}^{s^{*}} \\
\text { Online } \\
\text { channel }\end{array}$ & $\begin{array}{c}\mathbf{Q}_{2}^{*} \\
\text { Retail } \\
\text { channel }\end{array}$ & $\begin{array}{c}\text { Total } \\
\text { inventory } \\
\text { level } \\
\mathbf{Q}_{1}^{*}+\mathbf{Q}_{2}^{*}\end{array}$ & $\mathbf{Q}_{2}^{s^{*}}$ & $\begin{array}{c}\text { Total } \\
\text { inventory } \\
\text { level } \\
\mathbf{Q}_{1}^{s^{*}}+\mathbf{Q}_{2}^{s^{*}}\end{array}$ & $\mathbf{E}\left[\pi^{*}\right]$ & $\mathrm{E}\left[\pi_{1}^{\mathrm{s}^{*}}\right]$ \\
\hline \multicolumn{8}{|c|}{$\begin{array}{l}\text { Total demand function is uniform on }[0,1] \text { and } \\
c_{1}=0.8, c_{2}=1, s_{1}=0.01, s_{2}=0, g_{1}=0.5, g_{2}=0.3, p_{1}=5, p_{2}=5\end{array}$} \\
\hline 1 & 0.07329106 & 0.007454966 & 0.08074603 & 0.003813274 & 0.07710434 & 0.1658168 & 0.1065276 \\
\hline 2 & 0.1465821 & 0.0271869 & 0.173769 & 0.01431074 & 0.1608929 & 0.1250715 & 0.2284306 \\
\hline 3 & 0.2198732 & 0.05524635 & 0.2751195 & 0.03015862 & 0.2500318 & 0.04202877 & 0.3637384 \\
\hline 4 & 0.2931643 & 0.08768387 & 0.3808481 & 0.05014745 & 0.3433117 & 0.06968268 & 0.5106044 \\
\hline 5 & 0.3664553 & 0.12055 & 0.4870053 & 0.07321291 & 0.4396682 & 0.1983644 & 0.667325 \\
\hline \multicolumn{8}{|c|}{$\begin{array}{l}\text { Total demand function is uniform on }[0,5] \text { and } \\
=0.8, c_{2}=1, s_{1}=0.01, s_{2}=0, g_{1}=0.5, g_{2}=0.3, p_{1}=5, p_{2}=\end{array}$} \\
\hline 6 & 0.07329106 & 0.0004013913 & $\mathbf{0 . 0 7 5 8 8 9 6 7}$ & 0.0002006876 & 0.07349175 & 0.0821264 & 0.09816027 \\
\hline 7 & 0.1465821 & 0.005534498 & 0.1521166 & 0.002766485 & 0.1467828 & 0.128581 & 0.1965146 \\
\hline 8 & 0.2198732 & 0.02142825 & 0.2413014 & 0.01070653 & 0.2200739 & 0.1611267 & 0.2958142 \\
\hline 9 & 0.2931643 & 0.0542953 & 0.3474596 & 0.0271113 & 0.2933649 & 0.1695575 & 0.3974673 \\
\hline 10 & 0.3664553 & 0.1105339 & 0.4769892 & 0.05514742 & 0.366656 & 0.1424981 & 0.5035626 \\
\hline \multicolumn{8}{|c|}{ Total demand function is uniform on $[5,15]$ and } \\
\hline 11 & 0.07329106 & 0.009869532 & 0.0831606 & 0.004933551 & 0.07349175 & 0.0647587 & 0.09944475 \\
\hline 12 & 0.1465821 & 0.0435146 & 0.1900967 & 0.02174553 & 0.1467828 & 0.09509681 & 0.2025639 \\
\hline 13 & 0.2198732 & 0.1070578 & 0.326931 & 0.05348157 & 0.2200739 & 0.09455988 & 0.3112521 \\
\hline 14 & 0.2931643 & 0.2067126 & 0.4998769 & 0.1032245 & 0.2933649 & 0.0523953 & 0.4277389 \\
\hline 15 & 0.3664553 & $\begin{array}{l}0.3487837 \\
\end{array}$ & 0.715239 & 0.1740929 & 0.366656 & $\mathbf{0 . 0 4 0 3 7 8 3 7}$ & 0.5545909 \\
\hline \multicolumn{8}{|c|}{ Total demand function is uniform on $[0,1]$ and } \\
\hline 16 & 0.06124764 & 0.007454966 & 0.0687026 & 0.0002006876 & 0.06144832 & 0.1566096 & $\mathbf{0 . 0 3 8 8 9 6 7 9}$ \\
\hline 17 & $\mathbf{0 . 1 2 2 4 9 5 3}$ & 0.0271869 & 0.1496822 & 0.0002006876 & 0.122696 & 0.1092223 & $\mathbf{0 . 0 7 7 3 6 2 8 3}$ \\
\hline 18 & 0.1837429 & 0.05524635 & 0.2389893 & 0.0002006876 & 0.1839436 & 0.02466814 & 0.1158296 \\
\hline 19 & 0.2449905 & $\mathbf{0 . 0 8 7 6 8 3 8 7}$ & 0.3326744 & 0.0002006876 & 0.2451912 & 0.08085905 & $\mathbf{0 . 1 5 4 2 9 7}$ \\
\hline 20 & 0.3062382 & 0.12055 & 0.4267882 & 0.0002006876 & 0.3064389 & 0.1930956 & 0.192765 \\
\hline \multicolumn{8}{|c|}{$\begin{array}{l}\text { Total demand function is uniform on }[0,5] \text { and } \\
c_{1}=0.8, c_{2}=1, s_{1}=0.05, s_{2}=0, g_{1}=0.5, g_{2}=0.3, p_{1}=3, p_{2}=\end{array}$} \\
\hline 21 & 0.06124764 & 0.0004013913 & 0.06164903 & 0.0002006876 & 0.06144832 & $\mathbf{0 . 0 7 2 9 5 3 3 5}$ & 0.03845194 \\
\hline 22 & 0.1224953 & 0.005534498 & 0.1280298 & 0.0002006876 & 0.122696 & 0.1143534 & 0.07689772 \\
\hline 23 & 0.1837429 & 0.02142825 & 0.2051712 & 0.0002006876 & 0.1839436 & 0.1545514 & 0.1153434 \\
\hline 24 & 0.2449905 & 0.0542953 & 0.2992859 & 0.0002006876 & 0.2451912 & 0.1972339 & 0.153789 \\
\hline 25 & 0.3062382 & 0.1105339 & 0.4167721 & 0.0002006876 & 0.3064389 & 0.2504922 & 0.1922345 \\
\hline \multicolumn{2}{|c|}{$c_{1}=0.8, c_{2}=1, s_{1}=0.05, s_{2}=0, g_{1}=0.5, g_{2}=0.3, p_{1}=3, p_{2}=5$} & \multicolumn{6}{|c|}{ Total demand function is uniform on $[5,15]$ and } \\
\hline 26 & 0.06124764 & 0.009869532 & 0.07111717 & 0.0002006876 & 0.06144832 & 0.06586654 & $\mathbf{0 . 0 3 8 4 0 3 7 8}$ \\
\hline 27 & 0.1224953 & 0.0435146 & 0.1660099 & 0.0002006876 & 0.122696 & 0.1293173 & 0.07685471 \\
\hline 28 & 0.1837429 & 0.1070578 & 0.2908007 & 0.0002006876 & $\mathbf{0 . 1 8 3 9 4 3 6}$ & 0.2117118 & 0.1153056 \\
\hline 29 & 0.2449905 & 0.2067126 & 0.4517032 & 0.0002006876 & 0.2451912 & 0.3228704 & 0.1537566 \\
\hline 30 & 0.3062382 & 0.3487837 & 0.6550219 & 0.0002006876 & 0.3064389 & 0.477213 & 0.1922075 \\
\hline
\end{tabular}


We present the total inventory level for the two strategies when the market share via e-tail store, i.e. $\theta$ increases. In most cases, we find that the centralized strategy keeps more inventory than the Stackelberg case, which means that the service level with the centralized strategy would be the highest among the two strategies. In addition, we notice that as the market share of e-tail channel $\theta$ goes up, the total inventory level for the centralized strategy remains almost unaffected, but the inventory levels for the Stackelberg strategy increase rapidly. Thus, the manufacturer's production quantity with the centralized strategy is quite stable (significantly simplifying the capacity planning), whereas with the Stackelberg strategy, the manufacturer has to make significant changes to his production volume as the market share in the e-tail store increases.

\section{References}

1) Forrester Research, 2005. Topic Overview: US Online Retail.

2) Dinlersoz, E. M. and Hernandez-Murillo, R. (2005). The diffusion of electronic business in the United States. Federal Reserve Bank of St Louis Review; 87(1):11-34.

3) Hill, A., Collier, D., Froehle, C., Goodale, J., Metters, R. and Verma, R. (2002). Research opportunities in service process design. Journal of Operations Management; 20:189-202.

4) Lee, H. and Whang, S. (2001). Winning the last mile of e-commerce. Sloan Management Review; 42:54-62.

5) Cao, Y. and Zhao, H. (2004). Evaluations of etailers' delivery fulfillment: implication of firm characteristics and buyer heterogeneity. Journal of Service Research; 6:347-360.

6) Hua, Z. and Li, S. (2008). Impacts of demand uncertainty on retailer's dominance and manufacturer-retailer supply chain cooperations. OMEGA; 36:697-714.

7) Khouja, M. (2001). The evaluation of drop shipping option for ecommerce retailers. Computers and Industrial Engineering; 41:109-126.

8) Zhang, C., Tan G-W., Robb, D. J. and Zheng, X. (2006). Sharing shipment quantity information in the supply chain. OMEGA; 34:427-438.

9) Lee, W. (2005). A joint economic lot size model for raw material ordering, manufacturing setup, and finished goods delivering. OMEGA; 33:163-174.

10) Abdul-Jalbar, B., Gutierrez, J. and Sicilia, J. (2006). Single cycle policies for the one-warehouse $\mathrm{N}$-retailer inventory/distribution system. OMEGA; 34:196-208.

11) Seifert, R. W., Thoneman, U. W. and Sieke, M. A. (2006). Relaxing channel separation-integrating a virtual store into the supply chain.IIE Transactions; 38:917-931.

12) Tsay, A. and Agrawal, N. (2004). Channel conflict and coordination in the e-commerce age. Production and Operations Management; 13:93-110.

13) Parlar, M. (1998). Game theoretic analysis of the substitutable product inventory problem with random demands. Naval Research Logistics; 35:397-409.

14) Lippman, S. and McCardle, K. (1997). The competitive newsboy. Operations Research; 45:5465 . 